\title{
Nature AND PREVALENCE OF MENTAL ILLNESS IN THE WORKPLACE
}

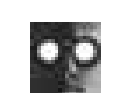

DISCUSSION PAPER

Carolyn S. Derwa, MPH, PHD

Health Economist, Health Systems Research and Consulting Unit, Centre for Addiction \& Mental Health

Associate Professor, Department of Psychiatry, University of Toronto

Alain Lesage, MD, MPHIL, FRCP(C), DFAPA

Vice-chair, Institute Advisory Board, Institute of Neurosciences,

Mental Health and Addictions, CIHR

Professor, Department of Psychiatry, University of Montréal and

Fernand-Seguin Research Centre, L-H Lafontaine Hospital, Montréal

Paula Goering, RN, PHD

Director, Health Systems Research \& Consulting Unit,

Centre for Addiction \& Mental Health

Professor, Department of Psychiatry, University of Toronto

Michele Caveen, MSc, ВSсРнма

Research Associate, Health Systems Research \& Consulting Unit, Centre for Addiction \& Mental Health 


\begin{abstract}
This discussion paper explores the state of knowledge about the prevalence of mental illness and its effect on the working population. Major trends in the literature are also commented on, and significant gaps in knowledge are identified.

Annually, 12\% of Canadians from 15 to 64 years suffer from a mental disorder or substance dependence. Few studies have examined the prevalence of mental disorders among Canadian workers. Results from Ontario estimate that monthly, about 8\% of the working population has a diagnosable mental disorder. Preliminary findings also indicate differences in the prevalence of mental disorders among workers with regard to occupation, age, sex, physical disorders, work environment and work-related stress.

Studies indicate that mental and emotional health problems are associated with staggering social and economic costs, which create a heavy burden on the workplace. About one-third of society's depression-related productivity losses can be attributed to work disruptions. The impact of mental illness on the workplace has been examined in terms of its effect on presenteeism, absenteeism and disability days. The presence of any of these has been used to indicate decreased productivity, the largest burden arising from presenteeism. In total, Canada annually loses about \$4.5 billion from this decreased productivity. Mental illness is also associated with short-term and long-term disability, which in turn is often related to insurance coverage. Mental illness related disability claims have doubled and mental illness accounts for $30 \%$ of disability claims, at a cost of $\$ 15$ to $\$ 33$ billion annually.

The needs of the working population and employers must be addressed. We must be aware of patterns of mental disorder among occupational groups and industry sectors. In addition, we must understand how the disability benefit structure impacts the prevalence as well as patterns of disability related to mental illness. Effective policies and programs must be based on solid evidence.
\end{abstract}

\section{Introduction}

Mental and behavioural disorders account for approximately $12 \%$ of all diseases and injuries worldwide (WHO 2001). For countries such as Canada, the percentage of all diseases and injuries attributable to mental disorders is closer to $25 \%$, with as much as $13 \%$ attributable to depression alone (Murray and Lopez 1997). In addition, it is expected that by the year 2020, depression will emerge as one of leading causes of disability globally, second only to ischaemic heart disease (WHO 1996).

Studies are beginning to show that mental and emotional health problems have staggering social and economic costs that place an especially heavy burden on the workplace (Dewa and Lin 2000; Kessler and Frank 1997; Lim et al. 2000; Perez and Wilkerson 1998). For example, Perez and Wilkerson (1998) found that $7 \%$ of all Canadian workers had absentee days that they attributed to mental and emotional problems. Compared to the rest of the working population, those with a psychiatric disorder will have a greater number of days during which they are either unproductive or unable to function at full capacity (Dewa and Lin 2000; Kessler and Frank 1997; Lim et al. 2000). 
Moreover, approximately $50 \%$ of those who miss work because of mental or emotional problems will take either 13 or more days off or will never return to their jobs (Perez and Wilkerson 1998).

About one-third of society's depression-related productivity losses can be attributed to these work disruptions (Greenberg et al. 1993). In 2001, workplace absenteeism due to mental health problems accounted for about $7.1 \%$ of the total payroll and was one of the principle causes of absences (Watson Wyatt Worldwide 2000). A recent estimate attributed $\$ 4.5$ billion in work-related productivity losses to depression (Stephens and Joubert 2001). Figures from the United Kingdom estimate that stress-related sickness absences result in an annual $\$ 4$ billion in workplace losses (Mental Health Organization 2003).

Although the effects of mental illness on the labour force are of critical concern, little is known about the working population disabled by mental disorders (Archambault et al. 2003). Though there have been population-based studies that characterize the general population suffering from psychiatric disorders, the extent to which the general population is representa- tive of the working population is still not clear (Berndt et al. 2000). The disorders may serve as a screen, keeping the most severely ill from participating in the workforce. Thus, the labour force population that is affected by mental disorders may have different characteristics than the population as a whole. The lack of this basic type of information makes it virtually impossible to develop policies or to plan workplace programs and interventions either to help prevent disabilities resulting from mental disorders or to promote return to work.

The purpose of this paper is to explore the state of knowledge about the prevalence and impact of mental illness on the working population. We will also comment on major trends in the literature as well as identify the significant gaps in knowledge.

\section{Defining the Working Population}

Statistics Canada (2002) defines the labour force as consisting of people who are 15 years or over and either are employed or are actively seeking work. Approximately $66.9 \%$ of Canadians (16 million people) fall under this definition. About $73.3 \%$ of men and $60.7 \%$ of women 15 years or older are in the labour force (see Table 1).

Table 1. Labour Market Participation by Sex and Age: Canada, 2002

\begin{tabular}{lcccccc}
\hline & \multicolumn{2}{c}{ Total } & \multicolumn{2}{c}{ Men } & \multicolumn{2}{c}{ Women } \\
Total & $\%$ & $\mathrm{n}$ (in 1,000s) & $\%$ & $\mathrm{n}($ in 1,000s) & $\%$ & $\mathrm{n}$ (in 1,000s) \\
15-19 Years & $66.9 \%$ & $16,689.4$ & $73.3 \%$ & $8,989.8$ & $60.7 \%$ & $7,699.6$ \\
20-24 Years & 54.4 & $1,113.7$ & 54.2 & 568.5 & 54.7 & 545.1 \\
25-34 Years & 86.0 & $1,627.5$ & 81.1 & 859.7 & 74.9 & 767.9 \\
35-44 Years & 87.4 & $4,543.9$ & 92.8 & $2,414.4$ & 82.0 & $2,129.5$ \\
45-54 Years & 83.8 & $3,807.6$ & 89.6 & $2,025.5$ & 78.0 & $1,782.2$ \\
55-64 Years & 53.7 & $1,634.9$ & 64.0 & 956.7 & 43.8 & 678.1 \\
65+ Years & 6.7 & 248.2 & 10.5 & 170.8 & 3.7 & 77.4 \\
\hline
\end{tabular}

Source: Statistics Canada. 2003. Labour Force Characteristics by Age and Sex. Accessed October 23, 2003. <http://www.statcan.ca/English/Pgdb/labor20a.htm>. 
Table 2. Prevalence of Selected Mental Disorders by Sex: Population 15-64 Years, Canada, Excluding Territories, 2002

\begin{tabular}{|c|c|c|c|c|c|c|}
\hline & \multicolumn{2}{|c|}{ Total Population, 15-64 yrs } & \multicolumn{2}{|c|}{ Men, 15-64 yrs } & \multicolumn{2}{|c|}{ Women, 15-64 yrs } \\
\hline & Number & Proportion & Number & Proportion & Number & Proportion \\
\hline \multicolumn{7}{|l|}{ Affective disorders } \\
\hline Major depressive disorder & $1,053,996$ & $5.0 \%$ & 388,047 & $3.6 \%$ & 665,949 & $6.3 \%$ \\
\hline Mania disorder & 192,644 & $0.9 \%$ & $-\mathrm{a}$ & - & 103,754 & $1.0 \%$ \\
\hline \multicolumn{7}{|l|}{ Anxiety disorders } \\
\hline Social phobia & 714,304 & $3.4 \%$ & 300,297 & $2.8 \%$ & 414,007 & $3.9 \%$ \\
\hline Agoraphobia & 166,579 & $0.8 \%$ & $-a$ & - & 129,045 & $1.2 \%$ \\
\hline Panic & 388,473 & $1.8 \%$ & $-\mathrm{a}$ & - & $-a$ & - \\
\hline \multicolumn{7}{|l|}{ Substance dependence } \\
\hline Alcohol dependence & 638,497 & $3.0 \%$ & 470,275 & $4.4 \%$ & 168,222 & $1.6 \%$ \\
\hline Illicit drug dependence & 170,793 & $0.8 \%$ & 122,008 & $1.1 \%$ & $-\mathrm{a}$ & - \\
\hline Any of the above & $2,495,108$ & $11.7 \%$ & $1,147,240$ & $10.8 \%$ & $1,347,868$ & $12.7 \%$ \\
\hline
\end{tabular}

Source: Statistics Canada. 2003. Canadian Community Health Survey: Mental Health and Well-Being. Accessed September 8, 2003. <http://www.statcan.ca/Daily/English/030903/d030903a.htm>. a Estimates not reported owing to large coefficient of variation.

\section{Prevalence of Mental Illness Mental Illness in the General Population}

According to the Canadian Community Health Survey (CCHS) 1.2, at least 11.7\% of the population between the ages of 15 and 64 years suffer from a mental disorder or substance dependence in any one year (see Table 2). In addition, more women than men have at least one disorder $(12.7 \%$ compared to $10.8 \%)$. Community surveys consistently find that the major categories of disorders from which people suffer are anxiety (i.e., generalized anxiety disorder, panic disorder), affective disorder (i.e., a major depressive episode) and substance use disorder (Offord et al. 1996).

Most of the work on mental illness in the general population focuses on depression. Between $4 \%$ to $6 \%$ of Canadians experience a major depressive episode during any one year (Murphy et al. 2000; Newman and Bland 1998; Offord et al. 1996; Statistics Canada 2003). In comparison, in the Canadian population between 15 and 64 years of age, the prevalence of other common chronic disorders are: diabetes at $2.3 \%$, high blood pressure

Table 3. Prevalence of Selected Chronic Disorders, by Age: Canada 2001

\begin{tabular}{|c|c|c|c|c|c|c|c|c|c|c|c|c|}
\hline & \multicolumn{2}{|c|}{ Depression } & \multicolumn{2}{|c|}{$\begin{array}{l}\text { High Blood } \\
\text { Pressure }\end{array}$} & \multicolumn{2}{|c|}{ Diabetes } & \multicolumn{2}{|c|}{$\begin{array}{c}\text { Arthritis/ } \\
\text { Rheumatism }\end{array}$} & \multicolumn{2}{|c|}{ Asthma } & \multicolumn{2}{|c|}{ Disabling Pain } \\
\hline & Number & $\%$ & Number & $\%$ & Number & $\%$ & Number & $\%$ & Number & $\%$ & Number & $\%$ \\
\hline Total & 976,015 & 4.8 & $1,434,376$ & 7.1 & 449,303 & 2.3 & $2,218,048$ & 10.9 & $1,663,276$ & 8.2 & 2594,441 & 2.9 \\
\hline $15-19$ yrs & ),360 & 4.2 & 0 & & 0 & & 0 & & 265,544 & 12.4 & 22 & 1.2 \\
\hline $20-24$ yrs & 138,341 & 7.2 & 0 & & 0 & & 38,33 & 2.0 & 235,057 & 12.2 & 0 & \\
\hline $25-34$ yrs & 238,321 & 5.8 & 73,558 & 1.8 & 40,224 & 1.0 & 156 & 3.8 & 381,942 & 9.3 & 91,400 & 2.2 \\
\hline $35-44$ yrs & 254,464 & 4.7 & 267,752 & 4.9 & 85,944 & 1.6 & 459,390 & 8.5 & 343,880 & 6.3 & 3179,772 & 3.3 \\
\hline $45-54$ yrs & 166,861 & 4.2 & 441,568 & 11.1 & 133,925 & 4.5 & 686,619 & 17.2 & 263,474 & 6.6 & $5 \quad 157,893$ & 4.0 \\
\hline $55-64$ yrs & 87,668 & 3.3 & 651,498 & 24.2 & 189,210 & 7.0 & 877,313 & 32.6 & 173,379 & 6.4 & 4594,441 & 5.2 \\
\hline
\end{tabular}

Source: Statistics Canada. 2001. Health Indicators, April 2001. Catalogue no. 82-221-XIE. Ottawa: Statistics Canada. 
at $7.1 \%$, arthritis and rheumatism at $10.9 \%$, asthma at $8.2 \%$ and disabling pain at 2.9\% (see Table 3) (Statistics Canada 2001). It has also been observed that there is an association between these chronic disorders and depression (Patten 1999; Wells et al. 1989). This offers insight into why depression is associated with disability; in fact, the World Health Organization (2001) has ranked depressive disorders as the leading cause of disability days in high income countries (see Figure 1).

\section{Mental Illness in the Labour Force} Unfortunately, the prevalence of mental disorders among the general working population in Canada has received relatively little attention. On the basis of results from Ontario (the country's most populous province, which is home to $37 \%$ of the population), during a 30 -day period, about $8.4 \%$ of the working population experience either an anxiety, affective or substance-related disorder or a combination of two of the three with or without a physical disorder (Dewa and Lin 2000) (see Table 4). Of the five categories of disorders, anxiety disorder and co-morbid physical and mental disorders have the highest prevalence. But, of the five, affective disorders are associated with the greatest disability (Goering et al. 1996).

In addition, as in the general population, there are differences in the prevalence of mental illness by sex and age (Marcotte et al. 1999; Stewart et al. 2003). It has been observed that among the employed population, major depressive disorders are twice as prevalent among women as among men (10.2\% compared to 5.9\%) (Marcotte et al. 1999). In addition, these disorders are more prevalent among middle-aged workers (i.e., 40-45 years) than among either younger (20-24 years) or older workers (50+ years) (Marcotte et al. 1999).

Preliminary findings also point to differences in the prevalence of the different types of mental disorders among

\section{Figure 1. Leading Causes of Disability Adjusted Life Years, High Income Countries, 2000}

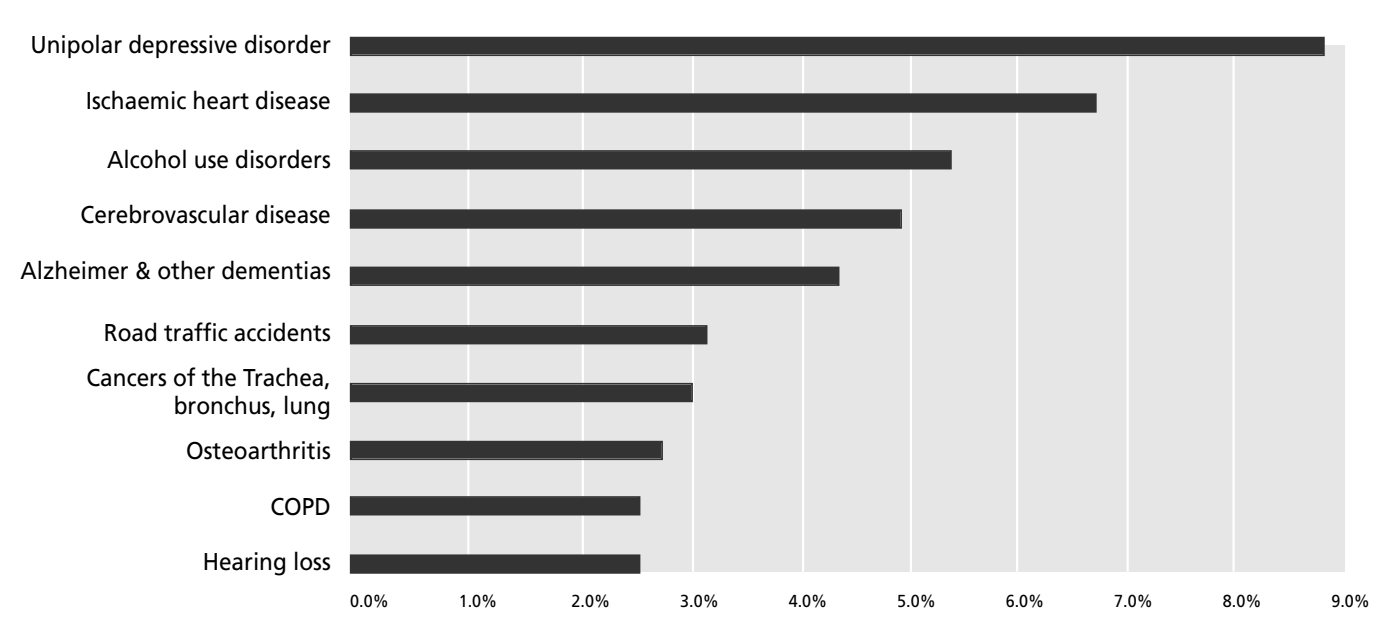

Source: World Health Organization. 2001. The World Health Report 2001 Mental Health: New Understanding, New Hope. Geneva: World Health Organization.

Note: High income countries, which are defined as in the World Health Report 1999, are the following: Andorra, Australia, Austria, Bahamas, Belgium, Brunei Darussalam, Canada, Cyprus, Denmark, Finland, France, Germany, Greece, Iceland, Ireland, Israel, Italy, Japan, Kuwait, Luxembourg, Monaco, Netherlands, New Zealand, Norway, Portugal, San Marino, Qatar, Republic of Korea, Singapore, Slovenia, Spain, Sweden, Switzerland, United Arab Emirates, United Kingdom and United States of America. 
Table 4. 30-Day Prevalence of Selected Mental Disorders and Physical Status by Occupational Groups: Working Population 15-54 years, Ontario 1990

\begin{tabular}{|c|c|c|c|c|c|c|}
\hline & $\begin{array}{l}\text { Anxiety } \\
\text { Disorder } \\
\text { Only }\end{array}$ & $\begin{array}{c}\text { Affective } \\
\text { Disorder } \\
\text { Only }\end{array}$ & $\begin{array}{c}\text { Substance } \\
\text { Abuse } \\
\text { Disorder } \\
\text { Only }\end{array}$ & $\begin{array}{l}\text { Co-morbid } \\
\text { Mental } \\
\text { Disorders } \\
\text { Only }\end{array}$ & $\begin{array}{c}\text { Physical } \\
\text { Disorder } \\
\text { Only }\end{array}$ & $\begin{array}{c}\text { Both } \\
\text { Physical } \\
\text { and Mental } \\
\text { Disorders }\end{array}$ \\
\hline $\begin{array}{l}\text { Occupational } \\
\text { Grouping }\end{array}$ & $\%$ & $\%$ & $\%$ & $\%$ & $\%$ & $\%$ \\
\hline TOTAL & 2.6 & 0.7 & 1.2 & 0.8 & 25.5 & 3.1 \\
\hline Professional & 4.3 & 0.0 & 0.1 & 1.0 & 25.1 & 1.2 \\
\hline High-level management & 5.7 & 0.3 & 0.4 & 0.5 & 16.8 & 1.8 \\
\hline Semi-professional & 1.2 & 2.0 & 0.2 & 0.0 & 22.9 & 3.5 \\
\hline Technician & 0.5 & 0.0 & 2.0 & 0.9 & 36.0 & 0.9 \\
\hline Middle management & 1.4 & 1.1 & 1.5 & 1.8 & 24.6 & 1.2 \\
\hline Supervisors & 1.6 & 0.0 & 1.7 & 0.4 & 18.8 & 2.7 \\
\hline Foremen & 0.8 & 0.0 & 2.7 & 0.0 & 35.2 & 4.5 \\
\hline Skilled clerical & 2.6 & 1.5 & 2.1 & 1.3 & 19.8 & 7.3 \\
\hline Skilled crafts and trades & 3.6 & 0.8 & 1.1 & 0.5 & 29.1 & 2.5 \\
\hline Farmers & 1.5 & 0.0 & 3.3 & 0.0 & 28.0 & 3.5 \\
\hline Semi-skilled clerical & 3.4 & 0.2 & 0.5 & 0.6 & 28.7 & 2.6 \\
\hline Semi-skilled manual & 1.5 & 0.2 & 1.5 & 0.0 & 27.0 & 2.8 \\
\hline Unskilled clerical & 3.3 & 0.0 & 0.2 & 2.6 & 22.9 & 3.3 \\
\hline Unskilled manual & 1.9 & 1.9 & 3.4 & 0.3 & 27.7 & 3.9 \\
\hline
\end{tabular}

Source: Dewa, C.S. and E. Lin. 2000. "Chronic Physical Illness, Psychiatric Disorder and Disability in the Workplace." Social Science and Medicine 51: 41-50.

occupational groups (see Table 4). For example, the Ontario Health Survey Mental Health Supplement found higher rates of co-morbid mental disorders among professionals, middle management and unskilled clerical workers (Dewa and Lin 2000). There have also been reports in the literature of a higher prevalence of mental disorders among particular groups, including night security guards and secretaries (Alfredsson et al. 1991; Garrison and Eaton 1992).

\section{Related Factors}

The differences in the prevalence of mental illnesses among the occupational groups raise the issue of the links between the work environment, stress and mental disorders. There is growing awareness of the prevalence of work-related stress. In a population-based sample of Canadians,
$30.8 \%$ said that most days at work were either quite a bit or extremely stressful. This feeling was reported by a higher proportion of women than men $-36.7 \%$ versus $29.0 \%$ (see Table 5) (Statistics Canada 2003).

Work-related stress is influenced by the work environment and the nature of the occupation as well as the sex of the worker (Bourbonnais et al. 1998; Bourbonnais et al. 2001; Karasek 1979; Siegrist 1996). It is also related to the presence of mental disorders. For instance, among a cross-sectional survey of 33,689 US women reporting on job strain and health status, those who indicated that they did high-strain work were observed to be at a higher risk of self-reported mental health problems (Amick et al. 1998). Grzywacz and Dooley (2003) found a fourfold increase in risk of depression associated with inadequate 
Table 5. Self-Rate Work Stress, by Sex: Population 15-64 years, Canada Excluding Territories, 2002

\begin{tabular}{lccccccc}
\hline & \multicolumn{3}{c}{$\begin{array}{c}\text { Total Population, 15-64 yrs } \\
\text { Number }\end{array}$} & $\begin{array}{c}\text { Men, 15-64 yrs } \\
\text { Proportion }\end{array}$ & Number & Proportion & Number, 15-64 yrs \\
Most days at work were: & & & & & & \\
$\quad$ Not at all stressful & $1,872,844$ & $10.6 \%$ & $1,095,258$ & $11.6 \%$ & 777,586 & $9.4 \%$ \\
$\quad$ Not very stressful & $3,341,620$ & $18.9 \%$ & $1,788,880$ & $19.0 \%$ & $1,552,739$ & $18.8 \%$ \\
A bit stressful & $6,876,456$ & $38.9 \%$ & $3,743,251$ & $39.8 \%$ & $3,133,205$ & $38.0 \%$ \\
Quite a bit stressful & $4,462,419$ & $25.3 \%$ & $2,253,420$ & $23.9 \%$ & $2,209,001$ & $26.8 \%$ \\
Extremely stressful & 967,610 & $5.5 \%$ & 482,913 & $5.1 \%$ & 484,697 & $5.9 \%$ \\
\hline
\end{tabular}

Source: Statistics Canada. 2003. Canadian Community Health Survey: Mental Health and Well-Being. Accessed September 8, 2003. <http://www.statcan.ca/Daily/English/030903/d030903a.htm>

employment environments in the California Work and Health Survey and a twofold increased risk in the US National Survey of Midlife Development. In Quebec, Bourbonnais and colleagues (2001) found that individuals who experienced workrelated stress were twice as likely to have a psychiatric condition as those who did not (23\% compared to $11 \%$ for men and 30\% compared to $15 \%$ for women).

The picture of mental illness in the workplace is becoming increasingly complicated. It is clear that there is a link between mental illness among workers and workrelated stress. In turn, both of these are likely to be related to occupation, the work environment and the sex of the worker.

There is also evidence of an association between mental illness and physical disorders. Yet, few studies have considered how all these various factors interact to affect the prevalence of mental disorders among workers. Even fewer have considered their relative contributions to disability in the workplace.

\section{Impact of Mental IIIness on the Labour Force}

Mental illness affects the working-aged population in two important ways. First, individuals with a mental illness are less likely to be employed (Ettner 2000;
Marcotte et al. 1999; Marcotte et al. 2000). In addition, there is evidence that the impact of mental illness on labour market participation may be different for men and women (Marcotte et al. 2000). A second consequence of mental illness is that individuals who are employed are less productive.

\section{Defining Disability}

In the literature, productivity is linked to the concept of disability. That is, it is assumed they are inversely related: the less disabled a worker is, the more productive and vice versa. The relationship between productivity and disability has been measured from at least two different perspectives: the worker's and the employer's. This distinction is especially important because there are two different sources of information - one more accessible than the other. Also, the standard used to measure disability and productivity influences the estimates of its impact.

\section{Worker-defined Disability}

Orme and Costa e Silva (1995) define disability as "any restriction or lack of capacity to perform an activity in a manner or within a range considered normal." With this definition, disability is a relative concept; it is judged against what is 
normal. Thus, the question can be asked of an individual with the answer based on his or her judgment. In the scientific literature, the following three types of questions are typically used to measure disability in population-based surveys (Dewa and Lin 2000; Kessler and Frank 1997; Lim et al. 2000; Stephens and Joubert 2001):

(1) How many days in the past 30 days have you been able to function only with extreme effort?

(2) How many days in the past 30 days have you been forced to cut back on activities or did not accomplish as much as usual?

(3) How many days during the past 30 days have you been completely unable to work or carry out normal activities?

Answers to the first two questions have been used to measure the number of days of reduced or partial productivity. These types of days have been referred to as extreme-effort days, work-cutback days or presenteeism days. All three terms are used to refer to days during which a worker is present at work but functioning at less than full capacity. In contrast, answers to the third question have been used to measure the number of total disability or absentee days - days during which the employee did not report to work; this is a standard less dependent upon individual judgment.

\section{Impact of Presenteeism and Absenteeism}

It has been observed that a significant proportion of the burden of mental disorders arises from presenteeism days (Dewa and Lin 2000; Kessler and Frank 1997; Lim et al. 2000). This disability pattern distinguishes mental disorders from chronic physical conditions. Chronic physical conditions are associated with total disability days, while the predominant effect of psychiatric disorders is on partial disability; in fact, psychiatric disorders were responsible for 23 times as many partial disability days as total disability days. In addition, disability days are different in the presence of a combination of psychiatric and physical disorders (Dewa and Lin 2000).

It is estimated that in a two-week period, among US workers, average presenteeism productivity loss due to depression is about four hours per week; that translates into $\$ 36$ billion (US) (Stewart et al. 2003). In contrast, the average depression-related absenteeism productivity loss is about 1.0 hour per week; that is equivalent to $\$ 8.3$ billion (US) (Stewart et al. 2003). Thus, depression-related decreases in workplace productivity result in annual losses of between $\$ 6$ and $\$ 60$ billion (Cdn) (Stephens and Joubert 2001; Stewart et al. 2003).

\section{Employer-defined Disability}

One of the major limitations of only using the worker's perspective is that it likely underestimates the workplace burden caused by mental illness. For instance, although absenteeism accounts for the days lost when the worker is absent, it does not account for the additional administrative costs the employer incurs as a result of the sick day or the cost of finding a substitute for the absent worker.

The worker's perspective also does not distinguish employee-defined disability days from employer-defined absentee days, short-term disability days and long-term disability days. Unlike total disability or 
partial disability, the concepts of shortterm and long-term disability are related to insurance coverage. Furthermore, there is no comprehensive governmental body governing these benefits. As a result, many of the disability benefits are employersponsored, often in conjunction with an insurance provider. This has two consequences. First, it increases the economic cost of disability. With the introduction of insurance, there are the additional costs of adjudicating and managing the claim. Second, these costs are magnified by the fact that there are multiple insurers.

\section{Short-Term and Long-Term Disability Benefits}

The diversity of insurers also has research implications. To understand the impact of short- and long-term disability related to mental disorders, it is necessary to seek claims data from every insurer. This requires the co-operation of each data holder, thereby adding another impediment to obtaining a comprehensive national picture (Dewa et al. 2000). In addition, the majority of companies track neither the incidence of claims nor the cause of disability (Watson Wyatt 1997); thus, there is no nationwide electronic database from which to gather information.

The disability picture from the employer's perspective becomes further complicated by at least three factors: (1) the philosophical issues surrounding the employer-sponsored benefits, (2) the criteria used to define whether a worker is disabled and (3) the impact of the types and structure of insurance benefits (e.g., premiums, co-payments, deductibles limits on number of visits covered and types of services covered), as well as other fringe benefits.

\section{Philosophical Issues and Disability}

Some concerns arise with employers and insurers because it is usually more difficult to prove the genesis of a mental disorder than of a physical disorder. As a result, there is some controversy about whether and how they should be covered under a worker's compensation scheme. For instance, under an occupational disease model, compensation for a disability is based on whether the disability arises from continuous exposure to hazardous conditions related to employment (Goldberg and Steury 2001). Yet, the most advanced etiological models of adult depression include factors related to genetic vulnerability, as well as developmental factors, neurobiological factors, childhood experiences, life events, chronic situations (e.g., a stressful work environment) and the presence of other disorders (Kendler et al. 2002). It is not yet understood what the due weight of each of these factors is and how they fit together. As a result, some companies are reluctant to provide psychiatric disability benefits. Because of the current state of the scientific knowledge about mental disorders, companies are left wondering to what extent disability benefits related to mental disorders are a form of worker's compensation rather than health insurance (Goldberg and Steury 2001).

\section{Variation in Disability Criteria}

As a result of different philosophical underpinnings, criteria and benefits vary. That is, there are no universal definitions of short- and long-term disability. This creates a major obstacle to comparing business sectors, occupations and nations. For example, a low rate of short- or longterm disability in one business sector compared to another could be a result either of a healthier workforce or of less 
generous benefits. That is, because shortand long-term disability is linked to insurance benefits, one quick and easy way for a company to reduce its rate of shortand long-term disability would be to curtail these types of benefits or stop offering them.

\section{Types and Structure of Employer-sponsored} Benefits

Finally, the types of disability benefits and criteria as well as other employeesponsored fringe benefits also influence workers' behaviour. For example, it has been observed that wages are positively related to return to work from long-term disability and negatively related to the length of the disability (Salkever et al. 2000a). The opposite holds for the relationship between the generosity of the benefits, on the one hand, and return to work and length of disability, on the other (Salkever et al. 2000b). That is, the generosity of the benefits is negatively related to return to work and positively related to the length of disability. Furthermore, age and fringe benefits have an effect on the use of disability benefits (Salkever et al. 2000a; Salkever et al. 2000b).

The potential influence of fringe benefits is further underscored by the fact that in many provinces, public health insurance will not reimburse independent non-physician providers for mental health services (Rochefort and Portz 1993). Many workers depend on employersponsored private insurance plans to provide mental health coverage that includes these non-physician providers. Still, such plans are generally limited to larger companies, annual dollar caps are low and only psychologists among nonphysician providers are eligible for reimbursement (Rochefort 1997).
In addition, substantial segments of the population lack adequate coverage for prescription drugs. It has been estimated that up to about a quarter of Canadians do not have insurance for prescription drugs (Canadian Institute for Health Information 2002). Yet, it has been observed that patterns of drug benefits use have been linked to return to work from short-term disability (Dewa et al. 2003a).

The lack of coverage for these essential outpatient treatments also contributes to the disparity between the need for mental health services and their use. For instance, the Canadian Community Health Survey (CCHS) 1.2 found that approximately two-thirds of Canadians with at least one mental disorder or substance dependence failed to contact a mental health professional (Statistics Canada 2003). This unmet need may have a variety of causes: shortages of appropriate services or trained and experienced service providers in local communities; under-diagnosis of disorders; fear of treatment and real or perceived stigma attached to mental illness or those who seek help; restrictive intake criteria; and barriers to obtaining mental health services that are due to distance or inadequate information (Dewa et al. 2003b). Not the least of these barriers is the outof-pocket cost of treatment (Newhouse et al. 1993). Indeed, these costs are intensified by the lack of insurance coverage.

\section{Impact of Short-Term and Long-Term Disability}

While much more knowledge is needed, a few studies have been conducted that begin to assist us in understanding the effect of short- and long-term disability on the workplace. They have consistently found that about 3\% of employees collect short- 
Table 6. Lost Workdays by Cause of Short-Term Disability, 1993-1995

\begin{tabular}{lccc}
\hline Reason for & Average Duration of & & \\
Short-term Disability & Short-Term Disability & Recidivism Rate & Total Lost Workdays \\
Depression & 43 days & $22 \%$ & 10,859 days \\
Diabetes & 33 days & $8.3 \%$ & 795 days \\
Hypertension & 25 days & $8.8 \%$ & 947 days \\
Ulcer & 24 days & $0.0 \%$ & 353 days \\
Asthma & 19 days & $32.7 \%$ & 1,432 days \\
\hline
\end{tabular}

Source: Conti D.J. and W.N. Burton. 1998. "Use of an Integrated Health Data Warehouse to Measure the Employer Costs of Five Chronic Disease States." Disease Management 1(1): 17-26.

term benefits (Dewa et al. 2002; Nystuen et al. 2001). Between $62 \%$ and $76 \%$ of shortterm disability episodes due to mental disorders are attributed to depression (Conti and Burton 1994; Dewa et al. 2002).

Moreover, the effects of short-term disability related to mental illness are also relatively large. For example, the average short-term disability episode related to depression is longer than one related to chronic physical disorders (Conti and Burton 1998; MetLife 2003) (see Table 6). In North American studies, it has been observed to range from 33 to 95.2 days; by a conservative estimate, that translates into 10 to 140 thousand total lost workdays (Conti and Burton 1994; Conti and Burton 1998; Dewa et al. 2002).

Over the last few years, the number of disability claims for mental disorders has been soaring. Between 1989 and 1994, according to the Health Insurance Association of America (1995), such claims doubled. In Canada, short- and long-term disability related to mental illness accounts for up to a third of claims and about $70 \%$ of the total costs $-\$ 15$ to $\$ 33$ billion annually (Sroujian 2003).

A large proportion of workers who experience a depression-related short-term disability are women (Conti and Burton 1994; Dewa et al. 2002; Nystuen et al. 2001). In addition, the majority of these workers are between 36 and 55 years of age and have invested a significant number of years in their workplaces (Dewa et al. 2002). Thus, the productivity loss is compounded by the fact that some of the most seasoned employees, who are in their mid-careers, become disabled.

Furthermore, as shown in Table 6, those with a history of depression-related short-term disability have a higher reoccurrence rate - ranging from $12 \%$ to $22 \%$ (Conti and Burton 1994; Conti and Burton 1998; Dewa et al. 2002). At the same time, about $76 \%$ of these workers return to work, whereas $8 \%$ go on to longterm disability and 16\% terminate their employment (e.g., they quit, retire or are terminated) (Dewa et al. 2002).

\section{Summary}

From the currently existing body of literature, we know that mental health problems present a serious threat to the nation's productivity. At the same time, we are only beginning to comprehend fully the prevalence and magnitude of the impact of mental health problems in the workplace. Much work still remains to be done.

There is a pressing need to devise strategies that meet the needs of the working population. This will be achieved only by understanding the patterns of mental disorder among the different 
occupational groups and industry sectors. With problems of manpower shortages constantly arising, it is important to know whether some occupations are at a more critical juncture than others, and whether we can solve some of the drain on human resources by targeting particular occupations or sectors.

We must also understand the association of employee-sponsored benefits and the prevalence of mental health problems in the workplace as well as patterns of disability related to mental illness. What are the trends in psychiatric disability? Is there a greater prevalence of one type of disability than another? To what extent do the employee-sponsored benefits - e.g., supplemental insurance, prescription drug benefits and employee assistance programs (EAPs) facilitate access to mental health services? If the impact of these services is large, should this encourage policy-makers to intervene by ensuring a basic minimum set of benefits for all workers? If there are large societal benefits to these services, should policymakers consider subsidizing them?

If we are to develop effective policies and programs, the answers to these questions must be based on solid evidence. But there is one looming impediment: the data needed for these inquiries have not been accessible. Only recently have we had access to a population-based epidemiological study that will enable us to examine the prevalence of mental disorders among the entire Canadian working population. At the moment, a nationally representative dataset showing disability from the employer's perspective does not exist. Furthermore, there has been little investment in building the links between academic research and business that would facilitate the development of such a dataset. Because of this, it is the area that we know the least about. Yet, these hurdles must be overcome. Indeed, in our knowledge-based economy, where the heavy lifting is done with our minds and not our backs, it is imperative that we find the solutions.

\section{References}

Ad Hoc Committee on Health Research Relating to Future Intervention Options World Health Organization. 1996. Investing in Health Research and Development. Geneva: World Health Organization.

Alfredsson, L., T. Akerstedt, M. Mattsson and B. Wilborg. 1991. "Self-Reported Health and Well Being amongst Night Security Guards: A Comparison with the Working Population." Ergonomics 34(5): 525-30.

Amick, B.C. III, I. Kawachi, E.H. Coakley, D. Lerner, S. Levine and G.A. Colditz. 1998. "Relationship of Job Strain and Iso-Strain to Health Status in a Cohort of Women in the United States." Scandinavian Journal of Work, Environment and Health 24(1): 54-61.

Archambault, E., G. Cote and Y. Gingras. 2003. Bibliometric Analysis of Research on Mental Health in the Workplace in Canada, 1991-2002. Montreal: Observatoire des sciences et des technologies.

Berndt, E., H.L. Bailit, M.B. Keller, J.C. Verner and S.N. Finkelstein. 2000. "Health Care Use and At-Work Productivity among Employees with Mental Disorders." Health Affairs 19(4): 244-56.

Bourbonnais, R., M. Comeau, M. Vézina and G. Dion. 1998. "Job Strain, Psychological Distress, and Burnout in Nurses." American Journal of Industrial Medicine 34: 20-28.

Bourbonnais, R., B. Larocque, C. Brisson and M.Vézina. 2001. "Contraintes psychosociales du travail.” Pp. 267-77 in Portrait social du Québec . LONGUEUIL Institut de la Statistique du Québec. Collection les Conditions de vie.

Canadian Institute for Health Information (CIHI). 2002. Health Care in Canada.

Retrieved August 16, 2002.

<http://secure.cihi.ca/cihiweb/hcic/hcic.html>

Conti, D.J. and W.N. Burton. 1994. "The Economic Impact of Depression in a Workplace." Journal of Occupational Medicine 36(9): 983-88.

Conti, D.J. and W.N. Burton. 1998. "Use of an Integrated Health Data Warehouse to Measure the Employer Costs of Five Chronic Disease States." Disease Management 1(1): 17-26. 


\section{HealthcarePapers Vol. 5 No. 2}

Dewa, C.S., P. Goering and E. Lin. 2000. "Bridging the Worlds of Academia and Business: Exploring the Burden of Mental Illness in the Workplace." The Economics of Neuroscience 2(6): 47-49.

Dewa, C.S., P. Goering, E. Lin and M. Paterson. 2002. "Depression-Related Short-Term Disability in an Employed Population." Journal of Occupational and Environmental Health 44(7): 62833.

Dewa, C.S., J.S. Hoch, E. Lin, M. Paterson and P. Goering. 2003a. "The Relationship between Guideline Concordant Treatment of Depression and Short-Term Disability." British Journal of Psychiatry 183: 507-13.

Dewa, C.S. and E. Lin. 2000. "Chronic Physical Illness, Psychiatric Disorder and Disability in the Workplace." Social Science and Medicine 51: 41-50.

Dewa, C.S., D. Rochefort, J. Rogers and P. Goering. 2003b. "Left Behind by Reform: The Case for Improving the Primary Care and Mental Health Systems Services for People with Moderate Mental Illness." Applied Health Economics and Health Policy 2(1): 43-54.

Ettner, S.L. 2000. “The Relationship between Labor Market Outcomes and Physical and Mental Health Exogenous Human Capital or Endogenous Health Production." Research in Human Capital and Development. Stamford, Connecticut: JAI Press.

Garrison, R. and W.W. Eaton. 1992. "Secretaries, Depression and Absenteeism." Women Health. 18(4): 53-76.

Goering, P., E. Lin, D. Campbell, M.H. Boyle and D.R. Offord. 1996. "Psychiatric Disability in Ontario.” Canadian Journal of Psychiatry 41: 564-71.

Goldberg, R.J. and S. Steury. 2001. "Depression in the Workplace: Costs and Barriers to Treatment." Psychiatric Services. 52(12): 1639-43.

Greenberg, P.E., L.E. Stiglin, S.N. Finkelstein and E.R. Berndt. 1993. "The Economic Burden of Depression in 1990." Journal of Clinical Psychiatry 54(11): 405-18.

Grzywacz, J.G. and D. Dooley. 2003. “'Good Jobs' to 'Bad Jobs': Replicated Evidence of an Employment Continuum from Two Large Surveys." Social Science and Medicine 56: 1749-60.

Health Insurance Association of America. 1995. Disability Claims for Mental and Nervous Disorders. Washington, DC: Health Insurance Association of America.

Karasek, R.A., Jr. 1979. “Job Demands, Job Decision Latitude and Mental Strain: Implications for Job Redesign.” Administrative Science Quarterly 24: 285-308.

Kendler, K.S., C.O. Gardner and C.A. Prescott. 2002. "Toward a Comprehensive Developmental Model for Major Depression in Women." American Journal of Psychiatry 159(7): 1133-45.

Kessler, R. and R.G. Frank. 1997. "The Impact of Psychiatric Disorders on Work Loss Days." Psychological Medicine 27: 861-73.

Lim, D., K. Sanderson and G. Andrews. 2000. "Lost Productivity among Full-Time Workers with Mental Disorders." Journal of Mental Health Policy and Economics 3: 139-46.

Marcotte, D.E., V. Wilcox-Gök and D. Redmon. 1999. "Prevalence and Patterns of Major Depressive Disorder in the United States Labor Force." Journal of Mental Health Policy and Economics 2: 121-31.

Marcotte, D.E., V. Wilcox- Gök and D.P. Redmon. 2000. "The Labor Market Effects of Mental Illness: The Case of Affective Disorders." Research in Human Capital and Development. Connecticut: JAI Press.

Mental Health Organization. 2003.

Retrieved November 26, 2003.

<http://www.mentalhealth.org.uk/html/content/ bkworkplace.cfm\#03>

MetLife. 2003. At Stake: More Than $\$ 500$ Billion Annually Related to Absences, Productivity and Healthcare. Retrieved November 5, 2003. <www.metlife.com/Applications/Corporate/WPS/ CDA/PageGenerator/0,1674,P2572>

Murphy, J.M., N.M. Laird, R.R. Monson, A.M. Sobol and A.H. Leighton. 2000. "Incidence of Depression in the Stirling County Study: Historical and Comparative Perspectives." Psychological Medicine 30: 505-14.

Murray, C.J. and A.D. Lopez. 1997. "Alternative Projections of Mortality and Disability by Cause, 1990-2020: Global Burden of Disease Study." Lancet 349: 1498-504.

Newhouse, J.P. and Insurance Group. 1993. "Central Findings and Policy Implications." Chap. 11 in Free For All? Lessons from the RAND Health Insurance Experiment. Cambridge, MA: Harvard University Press.

Newman, S.C. and R.C. Bland. 1998. "Incidence of Mental Disorders in Edmonton: Estimates of Rates and Methodological Issues." Journal of Psychiatric Research 32: 273-82. 
Nystuen, P., K.B. Hagen and J. Herrin. 2001. "Mental Health Problems as a Cause of LongTerm Sick Leave in the Norwegian Workforce." Scandinavian Journal of Public Health 29: 175-82.

Offord, D.R., M.H. Boyle, D. Campbell, G. Catlin, P. Goering, E. Lin and Y.A. Racine. 1996. "One-Year Prevalence of Psychiatric Disorder in Ontarians 15 to 64 Years of Age." Canadian Journal of Psycbiatry 41(9): 559-63.

Orme, J. and J.A. Costa e Silva. 1995. “The Impact of Psychopathology on Disability and Health Perceptions." Mental Illness in General Health Care: An International Study. Geneva: World Health Organization.

Patten, S.B. 1999. "Long-Term Medical Conditions and Major Depression in the Canadian Population." Canadian Journal of Psychiatry 44: 151-57.

Perez, E. and B. Wilkerson. 1998. Mindsets. Oakwood, Ontario: Homewood Centre for Organizational Health at Riverslea.

Rochefort, D.A. 1997. From Poorhouses to Homelessness: Policy Analysis and Mental Health Care, 2nd ed. Westport, CT: Auburn House.

Rochefort, D. and J. Portz. 1993. "Different Systems, Shared Challenges: Assessing Canadian Mental Health Care from a US Perspective." American Review of Canadian Studies 23 (Spring): 63-80.

Salkever, D.S., H. Goldman, M. Purushothama and J. Shinogle. 2000a. "Disability Management, Employee Health and Fringe Benefits, and Long-Term Disability Claim for Mental Disorders: An Empirical Exploration.” Milbank Quarterly 78: 79-113.

Salkever, D.S., J. Shinogle and M. Purushothama. 2000b. "Empirical Models of Employees' Disability Due to Injury Return-to-Work Outcome and Claim Duration under Private Long-Term Disability Insurance." Research in Human Capital and Development. Stamford: JAI Press.

Siegrist, J. 1996. "Adverse Health Effects of High Effort Low-Reward Conditions.” Journal of Occupational Health Psychology 1: 24-41.

Sroujian, C. 2003. "Mental Health Is the Number One Cause of Disability in Canada." Insurance Journal, August: 8.

Statistics Canada. 2001. Health Indicators, April 2001. Catalogue No. 82-221-XIE. Ottawa: Statistics Canada.
Statistics Canada. 2002. Economic Concepts

Labour Force. Retrieved October 23, 2003.

$<$ http://canadianeconomy.gc.ca/English/economy/ labour.html>

Statistics Canada. 2003. Canadian

Community Health Survey: Mental Health and

Well-Being. Retrieved September 8, 2003.

<http://www.statcan.ca/Daily/English/030903/

d030903a.htm>

Stephens, T. and N. Joubert. 2001. "The Economic Burden of Mental Health Problems in Canada." Chronic Diseases in Canada 22(1): 18-23.

Stewart, W.F., J.A. Ricci, E. Chee, S.R. Hahn and D. Morganstein. 2003. "Cost of Lost Productive Work Time among US Workers with Depression." Journal of the American Medical Association 289: 3135-44.

Watson Wyatt. 1997. Staying@ Work. Toronto: Watson Wyatt Canada.

Watson Wyatt Worldwide. 2000. Staying at Work 2000/2001 - The Dollars and Sense of Effective Disability Management. Catalogue No. W-377. Vancouver: Watson Wyatt Worldwide.

Wells, K.B., A. Stewart, R.D. Hays, M.A. Burnam, W. Rogers, M. Daniels, S. Berry, S. Greenfield and J. Ware. 1989. "The Functioning and Well-being of Depressed Patients." Results from the Medical Outcomes Study. Journal of the American Medical Association 262(7): 914-19.

WHO. 1996. See Ad Hoc Committee on Health Research....

WHO. 2001. See World Health Organization.

World Health Organization (WHO). 2001. The World Health Report 2001 Mental Health: New Understanding, New Hope. Geneva: WHO. 